\title{
AIDS virus nomenclature
}

SIR-Since July 1984 I have been writing on acquired immune deficiency syndrome (AIDS) for the London weekly free newspaper, Capital Gay. In the issue of 11 April I referred to a rumour that "human immune deficiency virus", "HIV" or "HIDV", was about to be proposed as the name for the causative agent. I fear that Robert Gallo is therefore mistaken in attributing first publication of this nomenclature to Luc Montagnier.

Your own objection to "HIV", that the "IV" might be confused with the roman "four", could be resolved by adopting the abbreviation "HIDV", for which there is an obvious precedent in "AIDS" for "acquired immune deficiency syndrome". However, combinations such as "HIV infection", "HIV disease", "HIV brain disease", "HIV lung disease" and "HIV lymphadenopathy" read far better than their "HIDV" equivalents.

As for the idea of "HTLV-III/LAV", fossilized forever, forget it. Are we expected to continue with "HTLV-IV/LAV3" and "LAV-2/HTLV-V"? What next?

While the name of the virus is totally irrelevant to the needs of those directly affected by it, an agreement to use the new name opens the way to an easilyunderstood terminology for the whole spectrum of conditions linked to this virus, which would be very useful to the agencies concerned with educating the public and health professionals about it.

Julian Meldrum

Capital Gay,

38 Mount Pleasant,

London $W C 1 X 0 A P, U K$

SIR-At a meeting on 22 and 23 May 1986 , the Executive Committee of the International Committee on Taxonomy of Viruses (ICTV) endorsed the name human immunodeficiency virus, recently proposed by a large majority of the members of a study group of ICTV, headed by Harold Varmus (J. Coffin et al. Nature 321, 10; 1986 and Science 232, 697; 1986), as appropriate for retrovirus isolates implicated as causing acquired immune deficiency syndrome (AIDS). The new name describes the host and a major biological property of the virus, recognizes the difference of the virus from isolates of human T-cell lymphotropic virus types 1 and II and avoids any controversy regarding priority of discovery of the virus and emotive connections of the virus with AIDS and its methods of transmission.

ICTV is working towards a uniform international nomenclature for viruses based on their taxonomy. Much still remains to be learned about the relationships of the human immunodeficiency virus with other retroviruses and therefore designation of an international name would be premature. However, the committee recommends the use of the name human immunodeficiency virus as the vernacular name to replace HTLV-III and LAV.

F. BROWN

(President, ICTV)

Wellcome Biotechnology Ltd,

Ash Road, Pirbright,

Woking, Surrey GU24 ONQ, UK

\section{French science policy}

SIR-France may be one of the richest countries in the world, but prosperity does not uniquely determine a country's scientific potential. The recent developments in science policy in France, and in particular the emphasis on applied sciences, is not a particularly creditable achievement for the policy-makers.

Every laboratory now seems to have been diverted towards applied science. In biology, chemistry, physics and mathematics, it is almost as if those responsible for policy have concluded that France has now done enough in basic science, and the time has come to exploit this knowledge for practical purposes. The result is debilitating for the laboratories previously concerned with basic science, now compelled to work in applied science to conform with the present fashion.

There is also a clear difference between the way in which those supported by the Centre National de la Recherche Scientifique (CNRS) establishment are equipped and the provision for ordinary academic scientists, who often work in the same laboratories. While CNRS groups have by no means everywhere attained the targets they have been set, they are nevertheless pampered with generous grants and sophisticated facilities that do not exist in ordinary university laboratories. Why should there be such a segregation?

In the basic science laboratories of the universities, scientists are to be found working on applied projects simply to earn the funds needed for their survival and to remain among the ranks of active scientists. No thought seems to have been given to this problem.

At the same time, research students are busily accumulating theses, a waste of money and time. These students are better served if they are trained in firstclass laboratories instead of being fed a huge bulk of theoretical science. Policymakers would find that if they abolished the present system, they could save time and money that could be used partly to safeguard French basic science.

Université Paul Sabatier.

Nitin K. SAKSENA

118 Route de Narbonne,

31062 Toulouse Cedex, France

\section{Chernobyl's message}

SIR-An important lesson of the Chernobyl disaster is that "probabilistic risk analysis" is a misapplied science. Its irrelevance to decision-making is now amply demonstrated. A core meltdown, designed to be less than a "one-in-a-million" chance in all reactors adopted by members of the International Atomic Energy Agency, has occurred twice within a decade.

Although such mathematical tools have their use in reactor design, they are still being applied uncritically in technology policy. In this respect they are dangerous, as they divert attention from the essential safety issues. These concern the hazard once realized (however improbably): control, and communication with and protection of the affected public. Doubtless misled by their own reassuring probabilistic predictions, Soviet scientists were caught unprepared in all respects, like their US colleagues at Three Mile Island.

British reactors are, on paper, exceptionally safe compared with Soviet reactors. But can the British public now believe that there is no need for detailed and well-rehearsed contingency plans for nuclear disasters? These should include not merely technical procedures on site, but also tested plans for communication with the public, and evacuation procedures for at-risk populations.

Developing such plans would involve scientists, public authorities and communities, in an extensive, open consultative dialogue. In the absence of such a programme, the nuclear industry's credibility will not be rescued by more reassurances couched in statistical rhetoric.

S.O. Funtowicz J.R. RAVETZ

Research Methods Consultancy Ltd, 158 Western Road, Sheffield SI0 1LD, UK

\section{No chance...}

SIR-As positive probabilities refer to events that can happen, negative probabilities presumably refer to events that cannot happen. The greater the probability that the event cannot happen (as distinct from being unlikely to happen), the higher the (negative) numerical value.

DAVE E. PARry

Department of Education,

Bell College of Technology,

Almada Street, Hamilton ML3 OJB, UK

\section{Erratum}

IN the letter "Too many fourth states of matter?" by J.M. Goldschvartz (Nature 320, 302; 1986), the second sentence in paragraph 2 should read: "Moreover, physicists should be aware that since 1940 the attribution was used to describe the superfluidity of liquid helium 4 and 3 (refs 3-6)". 